\title{
Spot Friction Stir Welding of Low Carbon Steel Plates Preheated by High Frequency Induction
}

\author{
Y.F. Sun", J.M. Shen, Y. Morisada, H. Fujii \\ Joining and Welding Research Institute, Osaka University, Ibaraki, Japan
}

\begin{abstract}
:
In this study, high frequency induction heating assisted spot friction stir welding was applied to $1.6 \mathrm{~mm}$ thick S12C low carbon steel plates. With the same welding parameter including an applied load of 2500kg, rotation speed of $800 \mathrm{rpm}$ and dwell time of $2 \mathrm{~s}$, the average grain size in the stir zone slightly increased from $12.9 \mu \mathrm{m}$ for the welds without preheating to $14.8 \mu \mathrm{m}$ when $10 \mathrm{~s}$ preheating was used. However, larger joint interface was formed within the stir zone of the welds with preheating and therefore the bonding strength can be significantly increased. As a result, the shear tensile load of the joint increased from $8 \mathrm{kN}$ to12.4 $\mathrm{kN}$ with preheating and the joint fractured through the plug failure mode rather than interfacial failure mode. It was revealed that the frictional heat generated between the rotating tool and the work-piece can be reduced to obtain sound welds by means of high frequency induction preheating.
\end{abstract}

Keyword: Spot friction stir welding; Preheating; Shear tensile test;

\footnotetext{
* Y.F. Sun (Yufeng Sun), Joining and Welding Research Institute, Osaka University, Japan Tel:81-6-68798653; Email: yfsun@jwri.osaka-u.ac.jp
} 


\section{Introduction}

As a relatively new process, spot friction stir welding (FSW) shows great potential to be a replacement for single point joining processes like resistance spot welding (RSW) and rivet technology. From the beginning of its emergence, it has been received considerable attention from the automotive and other industries. It was claimed that for spot FSW the use of energy significantly decreased and the investment cost was about $40 \%$ lower due to its minimal equipment requirement [1]. In addition, spot FSW is an environmentally friendly spot welding method due to the absence of any fumes or sparks. Today, a manufactured car requires 2000 to 5000 spot welds. To increase the fuel economy and improve the vehicle performance in the vehicle industry, spot FSW of light metals, like aluminum alloys, is being adopted by more and more transportation industries. Recently, with the development of high wear-resistance rotating tools, the spot FSW technique has also been expanded to some other materials with higher strength and higher melting point, such as the spot welding of steel [2-4]. For steel, the leading candidate for spot welding is still the RSW method. However, with the growing interest in the application of advanced high strength steels within the automotive architecture, spot FSW offers more reliable qualities than RSW during which the formation of a brittle microstructure occurs due to the high welding temperature and rapid cooling rate [5].

Although the rotating tool has also been developed and can be made of highly durable materials like WCbased alloy [6-8], PCBN [9-10], $\mathrm{Si}_{3} \mathrm{~N}_{4}$ [11-13], Ni alloy [14], Co alloy [15], Ir alloy etc [16-18], the wear of the rotating tool is still very severe. Generally a very high load need to be applied on the rotating tool and breaking of the tools often happens. Recently, the high consumption of costly rotating tools is also a big concern and has been investigated by some researchers. For example, Choi et al. [19] studied the wear of the WC-Co tool when subjected to the spot FSW of $0.6 \mathrm{~mm}$ thick low carbon steel plates. It was found that extreme wear occurred between the pin center and the edge, which resulted in the variation of the joint strength with the number of welds. The wear of the rotating tool will certainly result in the reduction of the penetration depth during the spot FSW process. Recently, Mitlin et al. studied the relationship between the weld strength and the penetration depth reduction caused by tool wear [20]. It was found that the peak strength could be reached at a certain penetration depth, and then decreased whether the penetration depth became smaller or larger. In addition, the fracture location also changes with the variation in the penetration depth.

With the attempt to extend the tool life and improve the welding efficiency, several preheating methods have been used to introduce more total heat input during the linear FSW process of high melting point metallic materials. For example, the preheating sources can come from the micro-plasma arc [21], electric resistance heat [22], high frequency induction [23], electromagnetic radiation, laser beam, etc. [24, 25]. Laser-assisted friction stir welding was invented and patented by Frank Palm in 2001, which has been successfully used in the FSW of nickel alloys and carbon steel [26, 27]. However, the reports about the use of laser beam as a preheating source during the spot FSW are still very limited.

In this paper, the spot FSW assisted by heat frequency induction was applied to the welding of $1.6 \mathrm{~mm}$ thick S12C steel plates, which is thicker than the steel plates generally used for spot welding. Therefore, a higher 
heat input is required and the wear of the rotating tool is severe during the welding process. After welding, the effect of the preheating on the welding parameter and the final microstructure and mechanical properties of the joints were investigated.

\section{Experimental Procedure}

In this study, commercial carbon steel $\mathrm{S} 12 \mathrm{C}$ plates with a thickness of $1.6 \mathrm{~mm}$ were subjected to the spot FSW process. The $\mathrm{S} 12 \mathrm{C}$ steel has the chemical composition listed in Table 1. The individual sheet is $100 \mathrm{~mm}$ in length and $30 \mathrm{~mm}$ in width, and two sheets were welded on an overlap area of $30 \times 30 \mathrm{~mm}^{2}$. Prior to welding, the steel sheets were cleaned with acetone to remove any impurities on the surface such as dirt, oil, etc. As for the preheating, high frequency induction heating equipment was installed besides the tool holder of the FSW machine. A water cooled induction coil was used to heat the surface of the work-piece. The entire welding process can be divided into four steps as shown in Fig. 1. First, the rotating tools and induction coil were installed about $5 \mathrm{~mm}$ above the sample surface and the induction coil was set exactly above the surface area to be welded. Second, after preheating for a certain time, the coil was quickly removed from the welding area and at the same time, the rotating tool was moved just above the welding area. Thirdly, the rotating tool was plunged into the sample at an applied load and starts to stir the sample. Finally after stirring the sample for a certain time, the rotating tool was retracted from the welds and the welding process was completed. During the welding process, a K-type thermal couple was used to measure the temperature, which was inserted between the two plates about $1 \mathrm{~mm}$ away from the rotating tool.

For the welding process, the steel plates were first placed on a steel back plate and clamped tightly. The welding process was then performed using a load-controlled FSW machine. The WC based rotating tool, which had a $12 \mathrm{~mm}$-dia concave shoulder, $4 \mathrm{~mm}$-dia unthreaded probe and $1.9 \mathrm{~mm}$ probe length, was used during all the welding processes. After several trials, a rotation speed of $800 \mathrm{rpm}$ and an applied load of $2500 \mathrm{~kg}$ were used to investigate the effect of preheating by high frequency induction. The frequency used in the induction heating system was $20 \mathrm{kHz}$ and the coil current was $400 \mathrm{~A}$. The selected preheating periods were $5 \mathrm{~s}$ and $10 \mathrm{~s}$. The time period for the stir welding by the rotating tool was $2 \mathrm{~s}$.

After welding, optical microscopy (OM) and electron backscattered diffraction (EBSD) were used to characterize the microstructure of the joints. The specimens for the OM observations were first mechanically polished with abrasive paper up to 1000 grit followed by a final polish with $1 \mu \mathrm{m} \mathrm{Al}_{2} \mathrm{O}_{3}$ suspensions. The polished steel specimens were then chemically etched with $4 \%$ Nital solution. The OM observations were carried out using an Olympus BX51M microscope. The EBSD measurements were carried out using a JEM7001FA field emission scanning electron microscope (FE-SEM) with a TSL orientation imaging system. The microstructures in the center of the stir zone after the second step as well as the base metal were also characterized by transmission electronic microscopy (TEM). For the TEM sample preparation, thin sheets were first cut at the desired locations and then mechanically polished to $100 \mu \mathrm{m}$. The thin polished sheets were finally twin-jet electro-polished to form an electron beam transparent thin film using a solution of 
$\mathrm{HClO}_{4}: \mathrm{CH}_{3} \mathrm{COOH}=1: 9$ at $30 \mathrm{~V}$ and $10{ }^{\circ} \mathrm{C}$. The thin films were observed using a JEOL 2100F TEM at 200kV. The Vickers hardness tests on the cross-sectional plane of the welds were carried out using an Akashi AAV500 Vickers hardness testing machine according to ASTM: E384-11. The shear tensile tests of the welds were carried out using an Instron-type testing machine with a crosshead speed of $1 \mathrm{~mm} / \mathrm{min}$, according to the JIS Z 3136:1999 standard [28].

\section{Experimental Results and Discussion}

\subsection{Thermal history}

Fig. 2 shows the effect of preheating on the temperature profile during the spot FSW process. Generally the temperature profile can be divided into three stages, namely, (1)the preheating stage; (2)the tool penetrating stage, and (3)the welding stage. For the welding without preheating as shown in Fig. 2(a), the temperature profile only contains the last two stages. The temperature of the materials started to increase when the tool touched the steel plate and gradually increased during the welding process. Due to the low thermal conductivity of carbon steel, the temperature was not constant during the $2 \mathrm{~s}$ welding period but continuously increased utill it finally reached a peak temperature of about $700{ }^{\circ} \mathrm{C}$ at the end of the welding process. The temperature then immediately dropped after the retraction of the rotating tool from the work-piece. As for the spot FSW with preheating, Fig. 2(b) and (c) show the temperature changes with a preheating of $5 \mathrm{~s}$ and $10 \mathrm{~s}$, respectively. The temperature started to increase during the preheating period. After preheating for $5 \mathrm{~s}$, the temperature reached about $550{ }^{\circ} \mathrm{C}$. When preheating for $10 \mathrm{~s}$, the temperature reached about $950{ }^{\circ} \mathrm{C}$. There was then a temperature drop after preheating due to removal of the coil and the plunging of the rotating tool. When the tool plunged into the steel plate and started to stir the materials, the temperature increased again. It was interesting to note that during the entire stirring period, the welding temperature was about $700{ }^{\circ} \mathrm{C}$, no matter whether or not preheating was used, and no matter how long the preheating was performed. Moreover, the temperature remained constant at about $700{ }^{\circ} \mathrm{C}$ during the $2 \mathrm{~s}$ welding period when preheating was used, which might favor the working stability of the rotating tools. From the temperature profile, it was found that the cooling rates after retraction of the rotating tools were different due to the elevated temperature of the sounding materials around the weld. The cooling rate before the temperature decreased to $500{ }^{\circ} \mathrm{C}$ was calculated according to

$$
\dot{T}=\left(T_{e}-500\right) / \Delta t
$$

where, $\dot{T}$ is the cooling rate of the weld, $T_{e}$ is the temperature at the end of the welding process, and $\Delta t$ is the time period when the temperature decreased to $500^{\circ} \mathrm{C}$ from the end of the welding process. According to the above equation, the cooling rate can be calculated to be $158 \mathrm{k} / \mathrm{s}$ for the welding without preheating. The cooling rate for the welds with preheating for $5 \mathrm{~s}$ and $10 \mathrm{~s}$ is quite similar, which were calculated to be $98 \mathrm{k} / \mathrm{s}$ and 102 $\mathrm{k} / \mathrm{s}$ for $5 \mathrm{~s}$ and $10 \mathrm{~s}$ preheating, respectively. 


\subsection{Microstructural characterization}

Fig. 3 shows the surface appearance of the welds obtained with and without preheating. All the welds were welded under the same welding conditions. For all the welds, it was observed that a depression was left by the tool shoulder and a keyhole formed at the center of the welds, which are the typical characteristics of the sample made by spot FSW. There is no obvious difference in the welded area among the three welds. However, on the top surface of the welds with preheating, a large black area around the welded area was observed. The black area was caused by oxidation on the sample surface at high temperature, because Ar gas was used only during the welding process.

Fig. 4 shows the effect of preheating on the cross-sectional macrostructure of welds. As a typical feature of the spot FSW processed sample, a keyhole was formed at the center of the welds and a flash was formed at the edge of the depression. The penetration depth into the welds increased when preheating was used and the penetration depth increased with an increase in the preheating time, which can be confirmed from the reduced thickness of the plates below the keyhole. For the weld without preheating, the thickness of the lower sheet below the keyhole was $0.87 \mathrm{~mm}$. However, the thickness at the same place decreased to $0.67 \mathrm{~mm}$ and $0.64 \mathrm{~mm}$ when the dwell time of preheating was $5 \mathrm{~s}$ and $10 \mathrm{~s}$, respectively. The flash at the edge of the depression also slightly increased when preheating was used. However, for all the welds, the area size of the stir zone was almost same, whenever preheating was used or not. In addition, the area size of the thermomechanically affected zone (TMAZ) slightly increased when the preheating was used. As a result, the length of the wellbonded joint interface increased, which is supposed to increase the weld strength.

During the spot FSW, the bonding condition of the joint interface between the two plates and the length of the joint interface play an important role in obtaining high weld strength [29]. Fig. 5 shows the effect of preheating on the formation of the joint interface between the two plates. For the welds prepared without preheating, the joint interface goes downward when getting closer to the keyhole as shown in Fig. 4(a). As a result, the joint interface only locates in the TMAZ. However, for the welds prepared with preheating, the penetration depth of the tool was large and more materials from the lower 1050 plates was extruded by the tool. The extruded material was forced to flow upward along the probe and push the joint interface to flow upward. As a result, the joint interface went upward when getting closer to the keyhole and a part of the joint interface can thus fall within the stir zone near the keyhole. Since the material in the stir zone experienced a severe plastic deformation and dynamic recrystallization period, the interfacial bonding of the two plates is supposed to be stronger than that in the TMAZ. A relatively lower plastic deformation of the material occurred in the TMAZ and the interfacial bonding is supposed to be mainly caused by high pressure.

Fig. 6 shows SEM images of the microstructure along the joint interface in the welds. Since the particles of surface impurities could be still found after the severe plastic hot deformation during the FSW, it helped to distinguish the joint interface from the newly constructed microstructure. For the welds without preheating, Fig. 6(a) shows the joint interface that existed in the TMAZ of the welds, because no joint interface was formed in 
the stir zone. The impurity particles on the original sample surface were finally distributed almost along the straight joint interface. In addition, some voids were observed around the particles in some places as shown in the inserted image in Fig. 6(a). The existence of the voids resulted in partial bonding between the two plates and certainly decreased the weld properties.

However, for the welds with the $10 \mathrm{~s}$ preheating, Fig. 6(b) shows the joint interface that existed in the stir zone of the welds. The joint interface was not straight but formed into a curved line in the stir zone. The curved joint interface revealed that severe plastic deformation or strong material flow occurred during the welding process. A lot of droplet-like particles can be found along the joint interface, indicating that local melting might have occurred. The phenomenon of local melting was also observed at the interface of the spot FSW of mild steel [13], in which large frictional heat could be generated due to the presence of impurity particles. Along the joint interface, some impurity particles can still be found and the grain size along the interface was remarkably smaller than those in other places of the stir zones. It reveals that the impurities at the joint interface may act as nucleation sites to trigger the occurrence of dynamic recrystallization. The particles that induced recrystallization nucleation have been found in the FSW of metals with ex-added particles [30]. In addition, no voids were observed along all the joint interfaces. It seems that local melting can enhance the interfacial bonding of the two plates.

Fig. 7 shows the effect of preheating on the microstructual evolution of the stir zone in the welds. For comparison, the microstructure of the base metal is also shown. The base metal has a coarse grain structure with an average grain size of about $25 \mu \mathrm{m}$ as shown in Fig. 7(a). In the stir zone of the welds, the average grain size significantly decreased due to the dynamic recrystallization during the FSW. In the stir zone of the welds obtained without preheating, the average grain size was about $12.9 \mu \mathrm{m}$ as shown in Fig. 7(b). However, the average grain size slightly increased to about $13.1 \mu \mathrm{m}$ and $14.8 \mu \mathrm{m}$ in the stir zone when the dwell time of preheating was $5 \mathrm{~s}$ and $10 \mathrm{~s}$, as shown in Fig. 7(c) and (d) respectively. Since the same welding condition was used for all the welding processes and the peak temperatures reached during the welding period were almost the same, the slightly larger average grain size in the stir zone with preheating was possibly caused by the slow cooling rate after welding. From the EBSD measurement results, the grain structure and the distribution of the misorientation were quite similar between the welds obtained with and without preheating. It seems that the preheating has little effect on the microstructure evolution in the stir zone of the welds. On the contrary, the microstructure in the stir zone is mainly dominated by dynamic recrystallization during the FSW. The grain size ranged from 12.9 to $14.8 \mu \mathrm{m}$ when different preheating time was used. However, the grain morphology showed no apparent different under the same welding condition, indicating that the grain size difference was mainly caused by the cooling effect after welding [31].

Fig. 8 shows the effect of the preheating on the microstructure evolution in the TMAZ of the welds. For the welds obtained without preheating as shown in Fig. 8(a), an obvious boundary can be discerned between the TMAZ and the BM due to the much smaller grain size in the TMAZ. However, for the welds with preheating as shown in Fig. 8(b) and (c), the boundary between the TMAZ and stir zone is not very clear because the grain 
size in the TMAZ increased due to the slow cooling rate. Fig. 8 (d) an (e) show the EBSD grain boundary (GB) map of the TMAZ in the welds without and with the 10 s preheating, in which the black, red and green lines indicated the grain boundary with a misorientation angle larger than $15^{\circ}$, between $15^{\circ}$ and $5^{\circ}$, and less than $5^{\circ}$, respectively. For the welds without preheating, a high fraction of low angle boundary formed due to the severe plastic deformation and the low angle boundary was aligned parallel to the direction of the material flow. However, with preheating for 10s, the fraction of the low angle boundary in TMAZ significantly decreased as shown in Fig. 8(e). With preheating, the material was exposed to a high temperature for a longer time, and the low angle boundary transformed into the high angle boundary due to the increased misorientation.

To further investigate the effect of the preheating on the microstructure of the welds, TEM observations were carried out at various specific zones in the welds with and without preheating. As typical examples, Fig. 9 shows the TEM images of the microstructure taken at different location in the welds. The base meal as shown in Fig. 9 (a) has a coarse grain structure with few dislocations and some carbide was distributed at the grain boundary. Fig. 9(b) shows the microstructure of the stir zone in the weld obtained with $10 \mathrm{~s}$ preheating, which has an equiaxial grain structure with a much smaller grain size than the base metal. The microstructure of the stir zone in the weld obtained without preheating showed a quite similar equiaxial grain structure as shown in Fig. 9 (c), except for the relatively smaller grain size and higher dislocation density. The TMAZ in the welds with preheating shows slightly elongated grain structure, together with some dislocations entangled near the grain boundary as shown in Fig. 9(d). However, the microstructure of the TMAZ in the welds without preheating showed a significantly elongated grain structure with a high density of dislocations as depicted in Fig. 9(e). The elongated grains were distributed parallel to each other, which is supposed to be aligned along the direction of the shear stress, or material flow. The difference in the microstructure of the TMAZ agrees well with the measurements by EBSD measurements.

\subsection{Mechanical properties}

Fig. 10 shows the effect of the preheating on the hardness distribution on the cross-sectional plane of the welds. Fig. 10(a) shows the locations on the plane where the measurements were carried out, in which the dotted-blue line and the dotted-red line indicated the hardness test on the center-line of the upper plate and the lower plate, respectively. For all the welds with and without preheating, the hardness in the stir zone is higher than that of the base metal due to the smaller grain size. For the welds with preheating, the hardness in the stir zone is about $180 \mathrm{HV}$, which is a slightly lower than the hardness of $195 \mathrm{HV}$ in the stir zone of the weld without preheating. Fig. 11(a) shows the load-displacement curves for the shear tensile tests of the spot welds obtained under various welding condition. The black curves shows that all the welds were prepared under the welding conditions of $2500 \mathrm{~kg} 800 \mathrm{rpm}$. It reveals that for the welds without HF, the specimen fractured through the interfacial failure mode at the relatively low strength of $8 \mathrm{kN}$ and small displacement. When the dwell time of preheating was $5 \mathrm{~s}$, the welds still fractured through the interfacial failure mode at an improved strength of about $10.5 \mathrm{kN}$. The interfacial fracture mode is generally not accepted due to its low ability to absorb energy. 
From the appearance of the fractured tensile specimen shown in Fig. 11(b), it reveals that the weld fractured into two pieces along the joint interface and no obvious plastic deformation of the welds can be observed. When the dwell time of preheating increased to $10 \mathrm{~s}$, the specimen showed a high strength of $12.4 \mathrm{kN}$ and fractured through the plug mode. The fractured specimen shown in Fig. 11 revealed that significant plastic deformation occurred in both the upper and lower plates along the welded area. The fracture initialized at the edge of the welded area and then propagated along the circumference of the depression. Finally the weld was torn into two pieces with a small part of the upper plate left on the welds.

For the sake of comparison, various welding conditions without preheating have been used to obtain the sound welds that fractured through plug mode. It was found that even when the applied load and rotation speed increased to $3000 \mathrm{~kg}$ and $1000 \mathrm{rpm}$, respectively, the spot welds still fractured through the interfacial failure mode at a low shear load. To minimize the heat input, the applied load and rotation speed need to be increased to $3500 \mathrm{~kg}$ and1000rpm, respectively, to guarantee the plug fracture of the welds. As typical examples, the loaddisplacement curves for the shear tensile tests are indicated as the red curves in Fig. 11. This means that much more heat input by friction between the tool and the sample is required to obtain a sound weld.

It is well known that the frictional heat can be simply calculated by the following equation [32],

$$
q_{0}=\int_{0}^{R} 4 \pi^{2} \mu P N r^{2} d r=Q=\frac{4}{3} \pi^{2} \mu P N R^{3}
$$

in which $\mu$ is the friction coefficient between the rotating tool and the work-piece, $R$ is the surface radius of the rotating tool, $N$ is the rotation speed and $P$ is the pressure. In this study, the variables are the applied load and the rotation speed. Based on the above equation, a much lower frictional heat input is necessary to obtain sound welds when preheating by a high frequency is used. On the other hand, it implied that the torque during welding can be decreased and the life of the rotating tools can be extended.

\section{Conclusions}

In this study, the spot FSW of $1.6 \mathrm{~mm}$ thick S12C steel was carried out with preheating by high frequency induction. The effect of the preheating on the microstructure and the mechanical properties were obvious and the following conclusions can be drawn:

1) Preheating by high frequency induction can be used during the spot FSW of steel plates as an extra heat resource.

2) The microstructure in stir zone of all the welds with preheating show a similar equiaxial grain structure with a slightly larger grain size due to the slow cooling rate after the welding process. Compared with the highly deformed grain structure with a high fraction of low angle boundary in TMAZ without preheating, the TMAZ with preheating contains a low fraction of a low angle boundary.

3) With preheating by high frequency, sound welds that fracture through the plug mode can be obtained at a relatively low applied load and low rotation speed. The shear tensile load can reach a maximum value of 
$12.4 \mathrm{kN}$. Compared with the welding process without preheating, the frictional heat can be reduced. A part of the heat for the sound welding can be compensated by high frequency induction heating.

\section{Acknowledgements:}

The authors wish to acknowledge the financial support of a Collaborative Research Based on Industrial Demand "Heterogeneous Structure Control: Towards Innovative Development of Metallic Structural Materials" by Japan Science and Technology Agency (JST), a program for development of innovative structural materials and technologies from Ministry of Economy, Trade and Industry, the Global COE Programs from the Ministry of Education, Sports, Culture, Science, and a Grant-in-Aid for Science Research from the Japan Society for Promotion of Science and Technology of Japan, ISIJ Research Promotion Grant. 


\section{References:}

[1] Sakano R, Murakami K, Yamashita K, Hyoe T, Fujimoto M, Inuzuka et al, in: Proceedings of the third international symposium symposium of friction stir welding, 2001.

[2] Fena Z, Santellab ML, David SA, Steel RJ, Packer SM, Pan T. Friction-stir spot welding of advanced highstrength steel: a feasibility study. SAE Trans 2005; 114: 592-598.

[3] Hovanski Y, Santella ML, and Grant GJ. Friction stir spot welding of hot-stamped boron steel. Scripta Mater 2007; 57(9): 873-876.

[4] Baek SW, Choi DH, Lee CY, Ahn BW, Yeon YM, Song SK. Structure-properties relations in friction stir welded low carbon steel sheets for light weight automobile body. Mater Trans 2010; 51(2):399-402.

[5] Khan MI, Kuntz ML, Su P, Gerlich A, North TH, Zhou Y. Resistance and friction stir spot welding of DP600: a comparative study. Sci Technol Weld Join 2007; 12(2): 175-182.

[6] Fujii H, Cui L, Tsuji N, Maeda M, Nakata K and Nogi K. Friction stir welding of carbon steels. Mater. Sci. Eng. A 2006; 429: 50-57

[7] Cui L, Fujii H, Tsuji N, Nogi K. Friction stir welding of a high carbon steel. Scripta Mater 2007; 56: 637-640.

[8] Saeid T, Abdollah-zadeh A, Assadi H and Malek Ghaini F. Effect of friction stir welding speed on the microstructure and mechanical properties of a duplex stainless steel. Mater. Sci. Eng., A, 2008; 496: $262-268$.

[9] Sorensen CD, Nelson TW, Packer SM. Proc. 3rd Int. Sympo. Friction Stir Welding, TWI, Kobe, Japan, (2001), CD-ROM.

[10] Collier M, Steel R, Nelson TW, Sorensen C, Packer S. Grade development of polycrystalline cubic boron nitride for friction stir processing of ferrous alloys. Mater. Sci. Forum, 2003; 426-432, 30113016.

[11] Ohashi R, Fujimoto M, Mironov S, Sato YS, Kokawa H. Effect of contamination on microstructure in friction stir spot welded DP590 steel. Sci. Tech. Weld. Join. 2009; 14: 221-227.

[12] Ishikawa T, Fujii H, Genchi K, Iwaki S, Matsuoka S and Nogi K. High Speed-High Quality Friction Stir Welding of Austenitic Stainless Steel. ISIJ Int. 2009; 49(6): 897-901.

[13] Sun YF, Fujii H, Takaki N, Okitsu Y. Microstructure and mechanical properties of mild steel joints prepared by a flat friction stir spot welding technique. Mater Design 2012; 37: 384-392.

[14] Mochizuki N, Takasugi T, Kaneno Y, Oki S, Hirata T. Proc. 9th Int. Sympo. Friction Stir Welding, TWI, Huntsville, USA, (2012), CD-ROM.

[15] Sato YS, Nagahama Y, Kokawa H. Microstructural studies of friction stir welded Zircaloy-4. Scripta Mater. 2012; 67: 241-244.

[16] Miyazawa T, Iwamoto Y, Maruko T, Fujii H. Development of Ir based tool for friction stir welding of high temperature materials. Sci. Tech. Weld Join. 2011; 16: 188-192. 
[17] Miyazawa T, Iwamoto Y, Maruko T, Fujii H. Development of high strength Ir based alloy tool for friction stir welding. Sci. Tech. Weld. Join. 2012; 17, 213-218.

[18] Fujii H, Sun YF, Kato H. Microstructure and Mechanical Properties of Friction Stir Welded Pure Mo Joints. Scripta Mater. 2011; 64: 657-660.

[19] Choi DH, Lee CY, Ahn BW, Yeon YM, Song K. Frictional wear evaluation of WC-Co alloy tool in friction stir spot welding of low carbon steel plates. Int. J. Refra Metal \& Hard Mater. 2009; 27: 931-936.

[20] Mitlin D, Radmilovic V, Pan T, Chen J, Feng Z, Santella ML. Structure-properties relations in spot friction welded 6111 aluminum. Mater Sci Eng A 2006; 441: 79-96.

[21] Liu HJ, Gao N, Feng JC. Friction stir welding assisted by micro-plasma arc. Proc of the $6^{\text {th }}$ Int Symposium on Friction stir welding. Montreal, Canada, October 10-13, 2006.

[22] Aota K, Okamura H, Sato K. Friction stir welding method and apparatus for reducing the friction force. EP1430986, 2004.

[23] Mach M, Schulbe H, Nacke B. Investigation and design of induction assisted welding processes. Przeglad elektrotecniczny 2008; 84(11): 228-231.

[24] Robert R. Rice, Jan Vetrovec. Radiation assisted friction welding. US6776328B2, 2004.

[25] Palm F. Laser supported friction stir welding method. US6793118, 2001.

[26] Song KH, Tsumura T, Nakata K. Development of Microstructure and mechanical properties in laser-FSW hybrid welded Inconel 600. Mater Trans 2009; 50(7): 1832-7.

[27] SunYF, Konishi Y, Kamai M, Fujii H. Microstructure and mechanical properties of S45C steel prepared by laser-assisted friction stir welding. Mater Des, 2013; 47: 842-849.

[28] JIS Z 3136, Specimen dimensions and procedure for shear testing resistance spot and embossed projection welds. Japanese Industrial Standard, 1999; 305-313.

[29] Yin YH, Ikuta A, North TH. Microstructural features and mechanical properties of AM60 and AZ31 friction stir spot welds. Mater Design, 2010; 31: 4764-4776.

[30] Sun YF, Fujii H. The effect of SiC particles on the microstructure and mechanical properties of friction stir welded pure copper joints. Mater Sci Eng A, 2011; 528: 5470-5475

[31] Cui GR, Ma ZY, Li SX. The origin of non-uniform microstructure and its effects on the mechanical properties of a friction stir processed Al-Mg alloy. Acta Mater, 2009; 57: 5718-5729.

[32] Frigaard Q, Grong Q and Midling OT. A process model for friction stir welding of age hardening aluminum alloys. Metall. Mater. Trans. A. 2001; 32: 1189-200. 


\section{Captions of Figures and Tables}

Table 1. Chemical composition of S12C steel

Fig. 1 (a) Outline showing the principle of the preheat-assisted spot FSW process; and (b) photos taken during the spot FSW process.

Fig. 2 The temperature measurement during the spot FSW process; (a) No preheating; (b) $5 \mathrm{~s}$ preheating; and (c) $10 \mathrm{~s}$ preheating.

Fig. 3 The appearance of the welds with preheating for (a) $0 \mathrm{~s}$; (b) $5 \mathrm{~s}$; and (c) $10 \mathrm{~s}$.

Fig. 4 The cross-sectional macrostructure of the welds with preheating for (a) $0 \mathrm{~s}$; (b) $5 \mathrm{~s}$; and (c) $10 \mathrm{~s}$.

Fig. 5 The variation in the joint interface of spot FSW with preheating for (a) $0 \mathrm{~s}$; (b) $5 \mathrm{~s}$; and (c) $10 \mathrm{~s}$. (SZ: stir zone)

Fig. 6 Microstructure of the joint interface (a) in the TMAZ of the welds without preheating; (b) in the stir zone with $10 \mathrm{~s}$ preheating.

Fig. 7 Microstructure characterization of the stir zone obtained at different welding conditions. (a) Base metal; (b) no preheating; (c) 5 s preheating; (d) 10 s preheating; (e) IPF-map of stir zone without preheating; (f) IPF-map of stir zone with $10 \mathrm{~s}$ preheating; and (g) Misorientation angle distribution of the stir zone welded without preheating and with $10 \mathrm{~s}$ preheating.(HF: high frequency)

Fig. 8 Microstructure of the TMAZ of the sample after spot FSW. (a) no preheating; (b) $5 \mathrm{~s}$ preheating; (c) $10 \mathrm{~s}$ preheating; (d) no preheating; (e) 10 s preheating; and (f) Misorientation angle distribution of TMAZ without and with $10 \mathrm{~s}$ preheating. (BM: base metal)

Fig. 9 TEM images showing the microstructure of various specific zones in the welds. (a) Base metal; (b) stir zone with $10 \mathrm{~s}$ preheating; (c) stir zone without preheating; (d) TMAZ with $10 \mathrm{~s}$ preheating; and (e) TMAZ without preheating.

Fig. 10 Hardness distribution on the cross-sectional plane of the preheating assisted spot FSW. (a) without preheating; (b) 5 s preheating; and (c) 10 s preheating.

Fig. 11 (a) Shear tensile tests of the spot welds obtained at different welding conditions; and (b) appearance of the fractured specimens showing different fracture mode. 
Table 1.

\begin{tabular}{c|c|c|c|c|c}
\hline S12C & $\mathrm{C}$ & $\mathrm{Mn}$ & $\mathrm{P}$ & $\mathrm{S}$ & $\mathrm{Fe}$ \\
\hline mass\% & 0.12 & 0.29 & 0.008 & 0.02 & Bal. \\
\hline
\end{tabular}


Figures

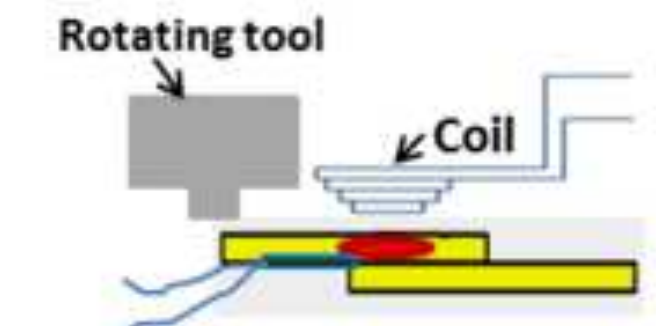

Thermocouple

1. Preheated by induction coil
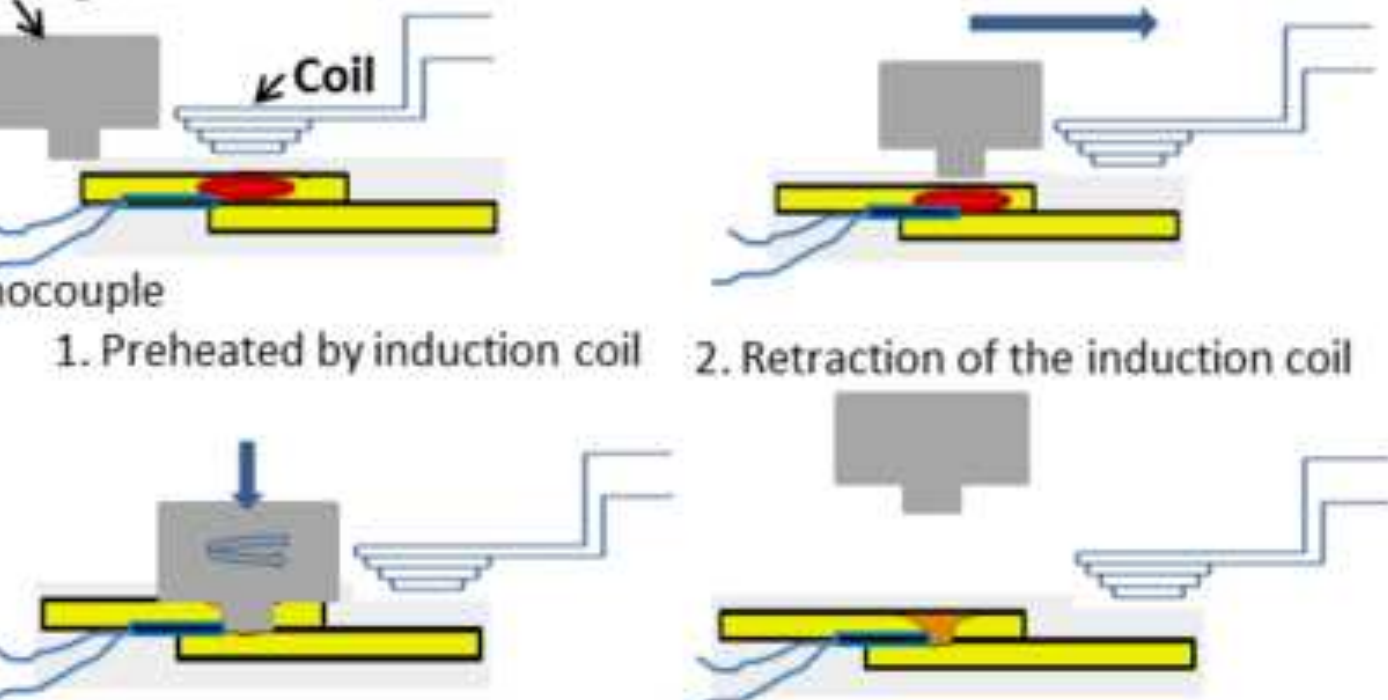

2. Retraction of the induction coil

3. Penetration of the tool

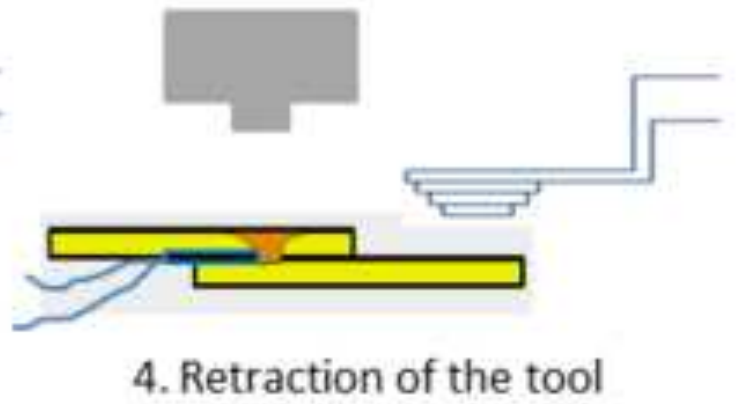

(a)

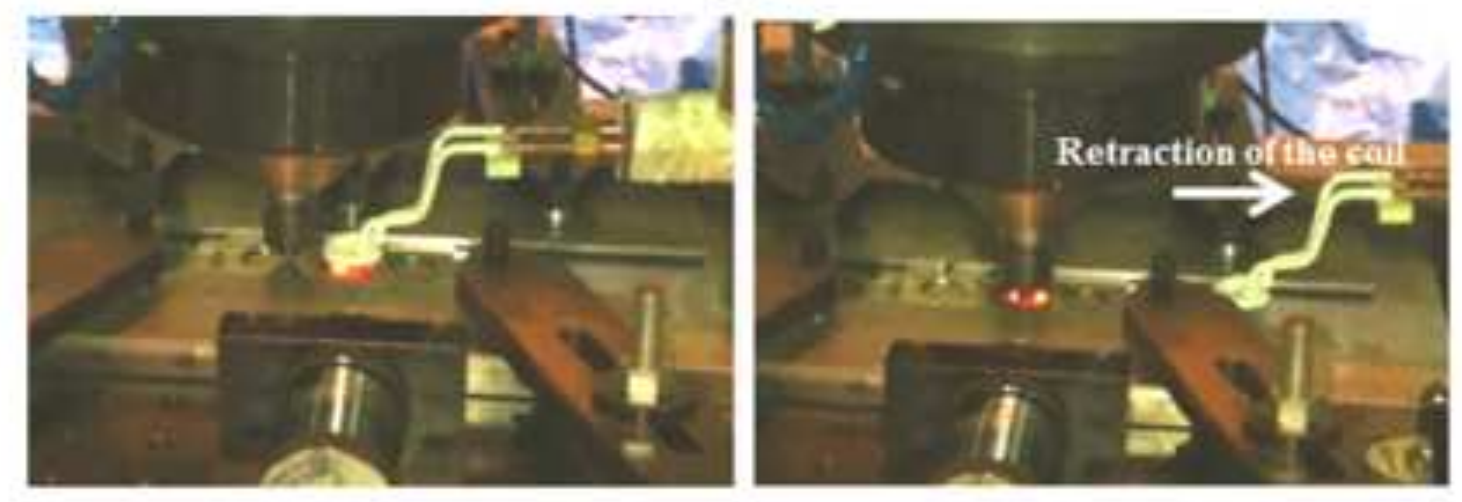

(b)

Fig. 1 

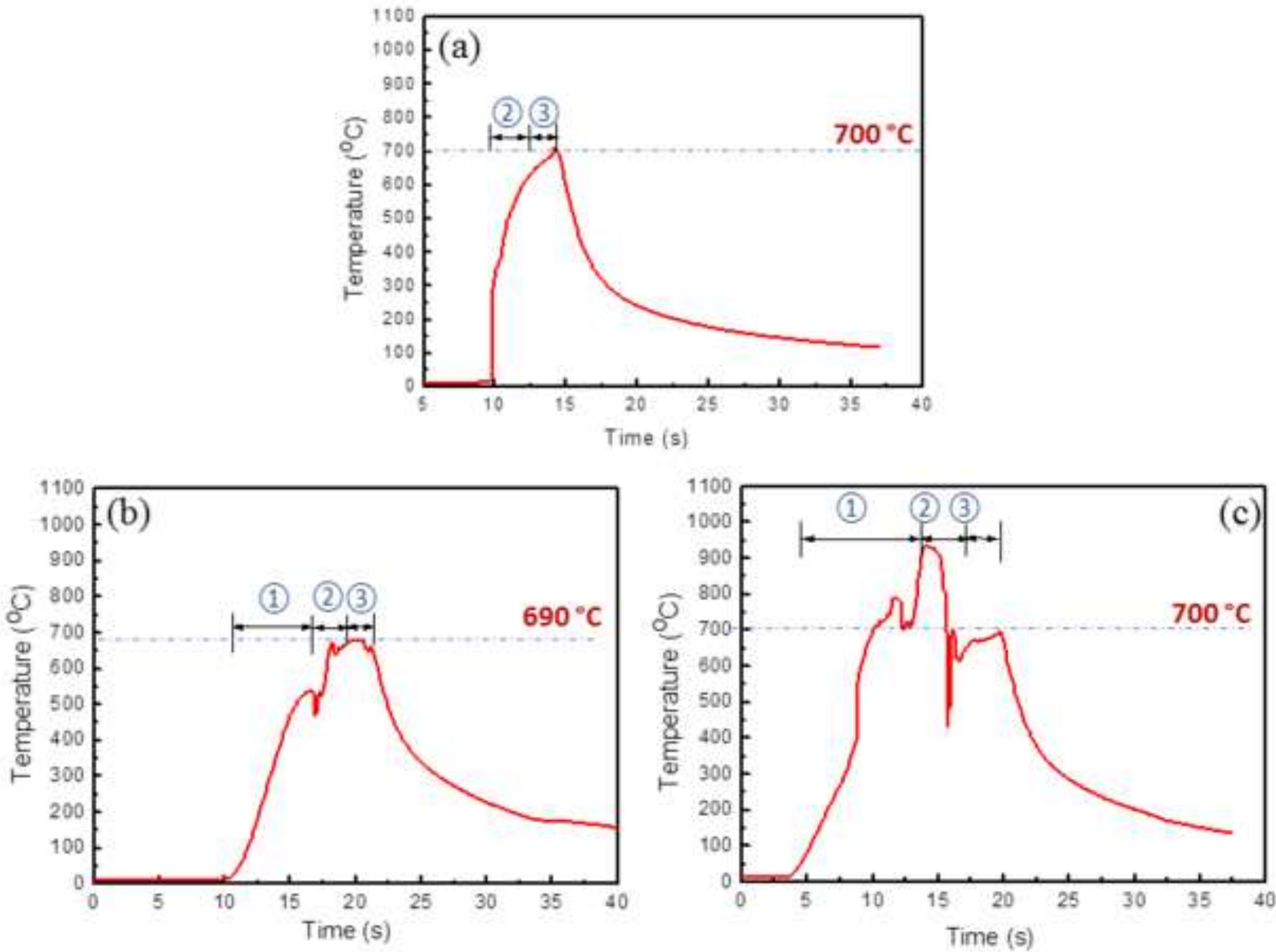

Fig. 2 


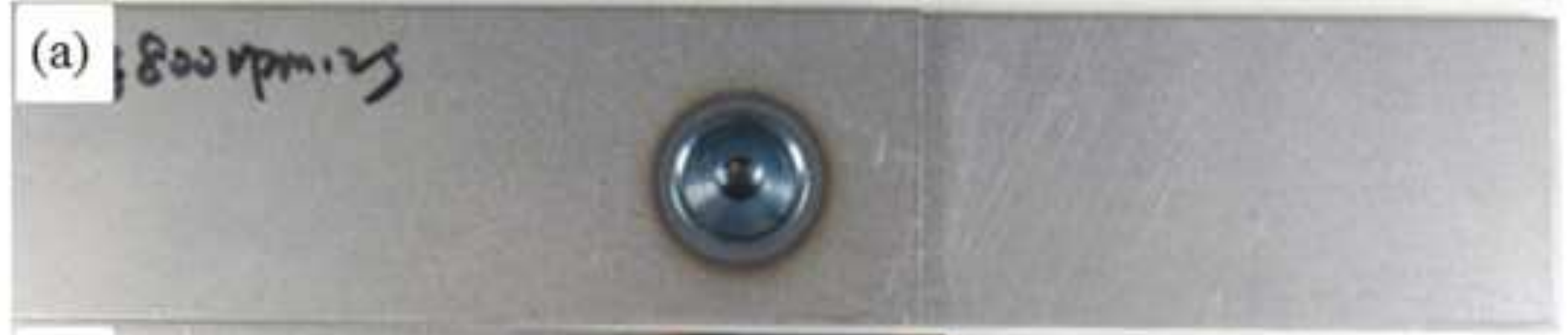

(b) orpma 25

SHT

(c) 1 sourpary

, IT

Fig. 3 

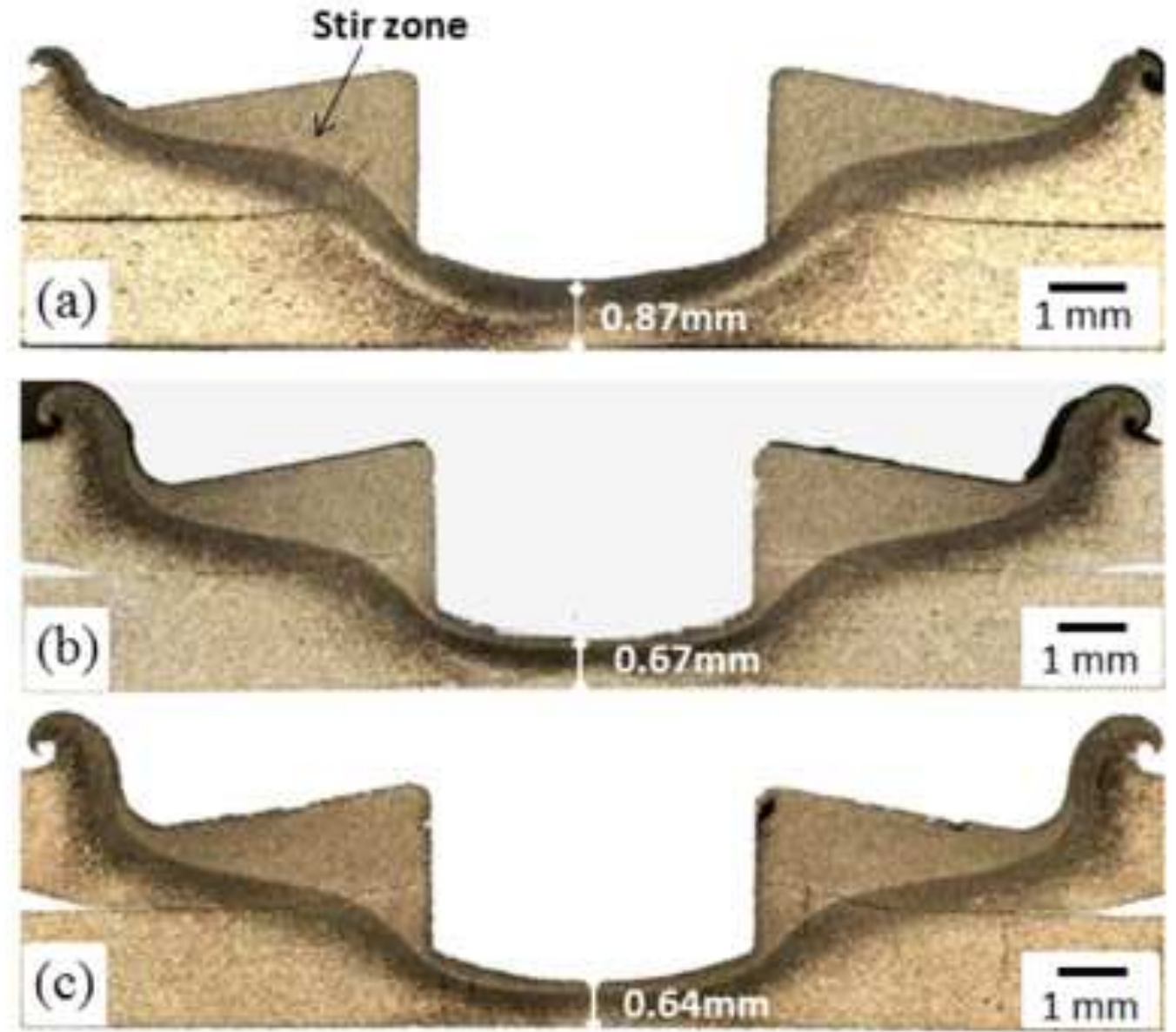

Fig. 4 


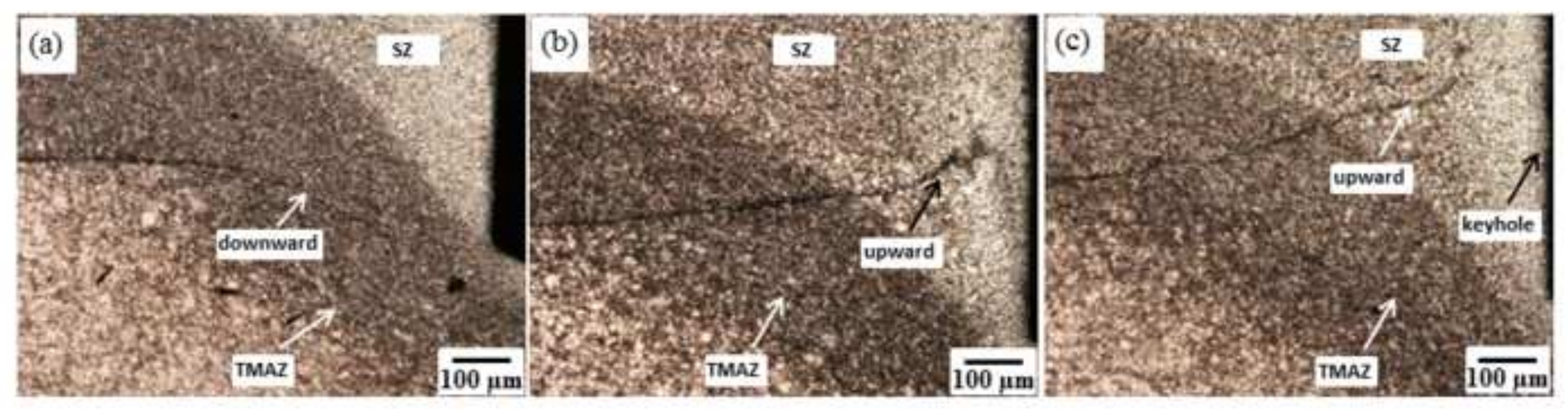

Fig. 5 


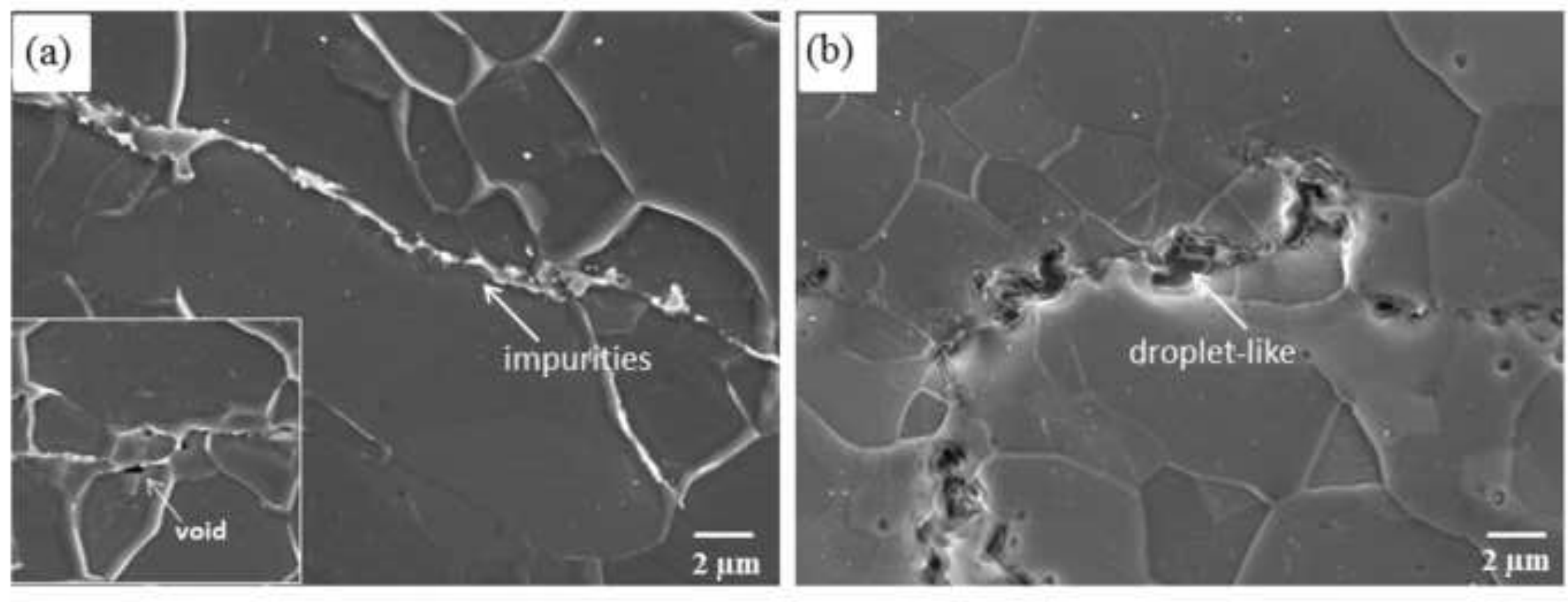

Fig. 6 

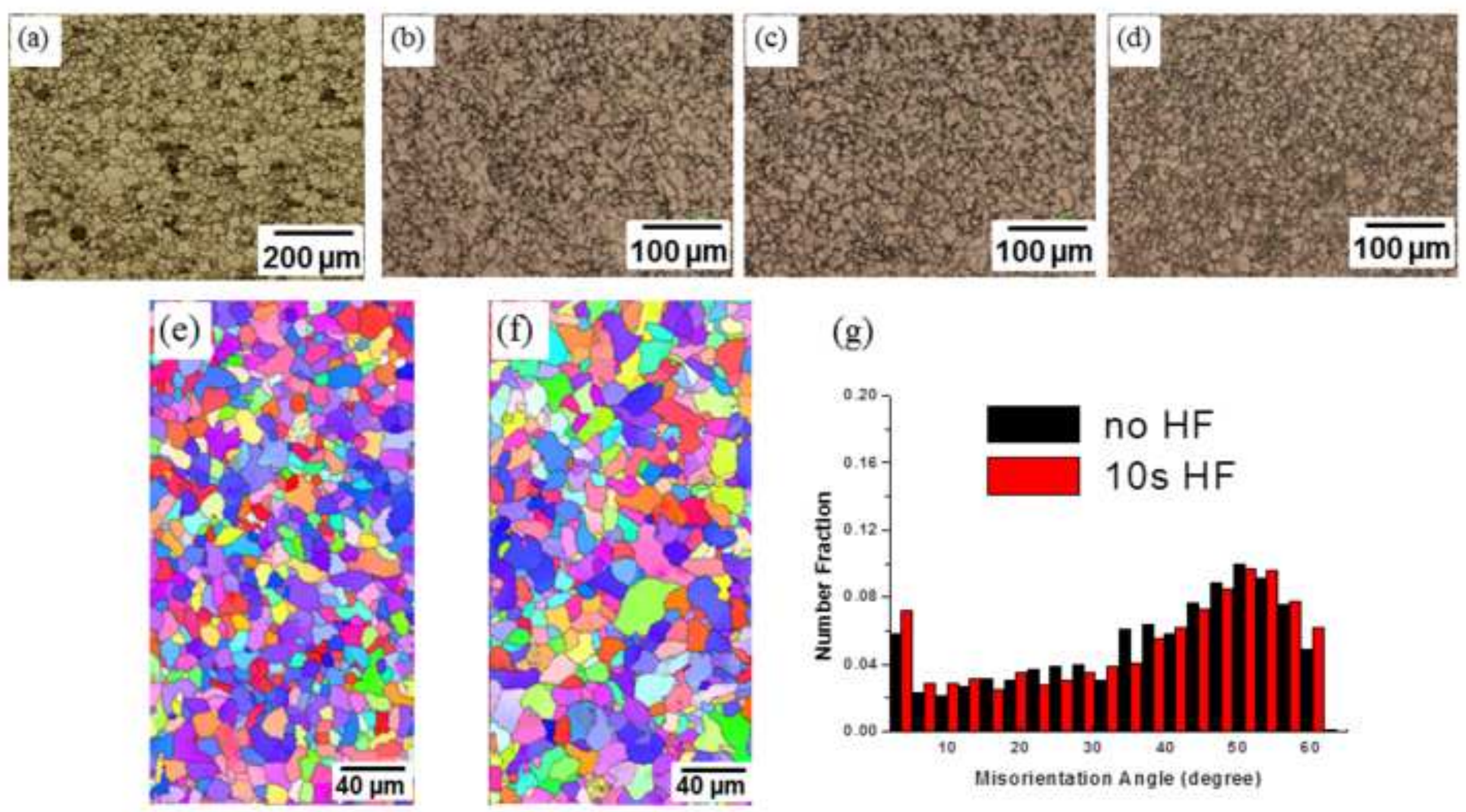

(g)

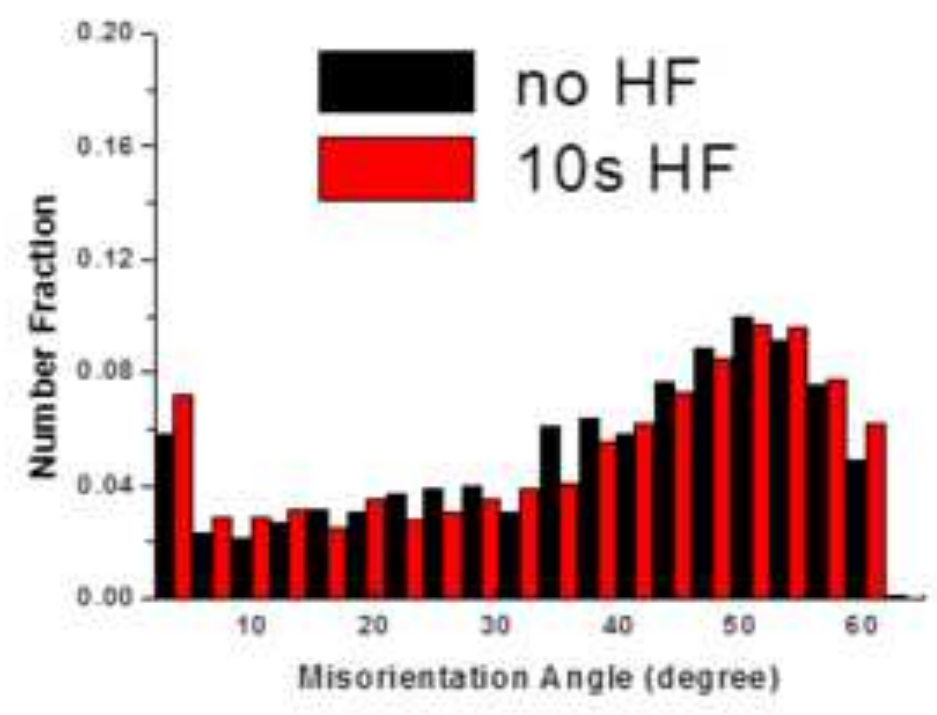

Fig. 7 

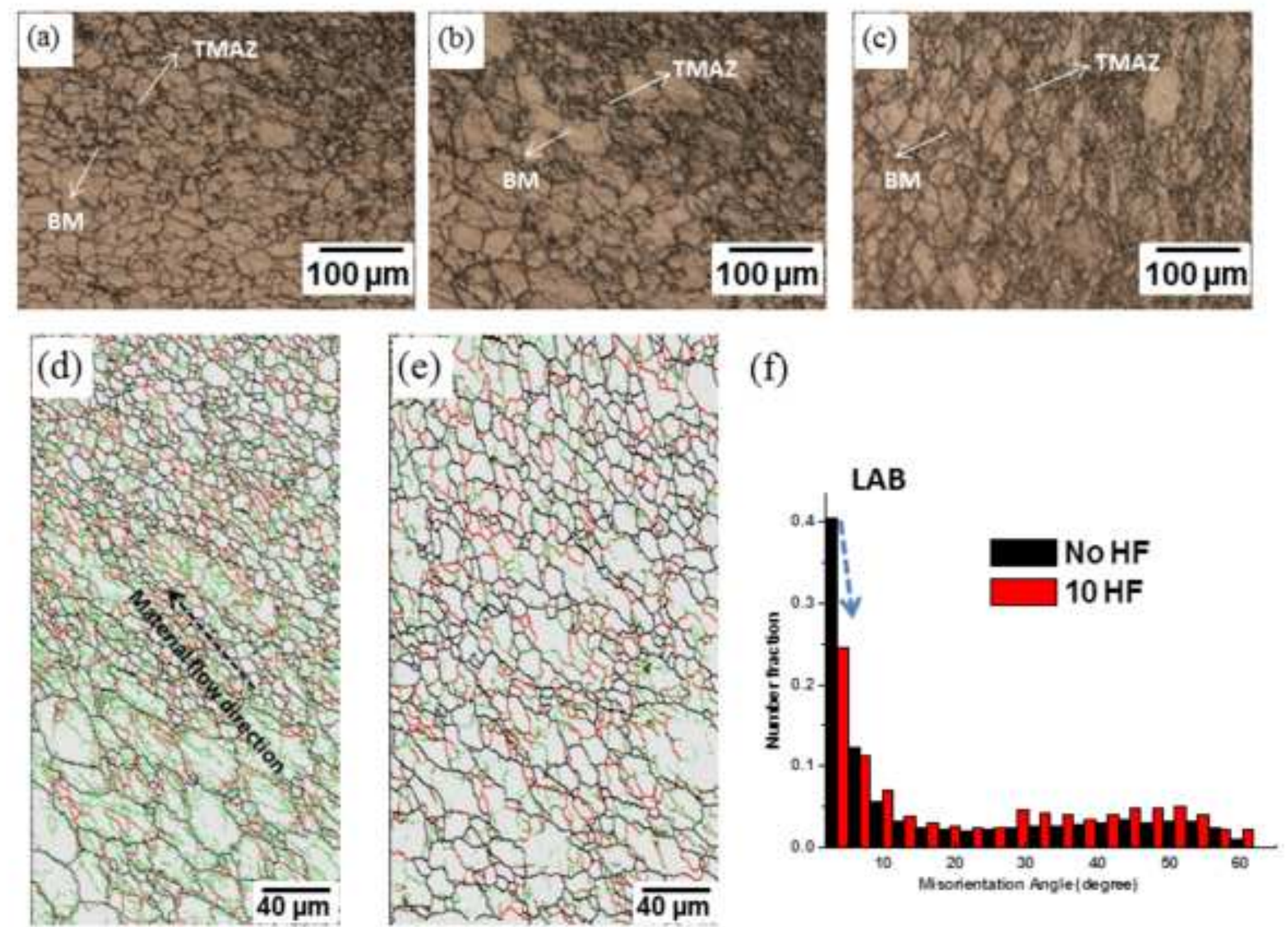

Fig. 8 


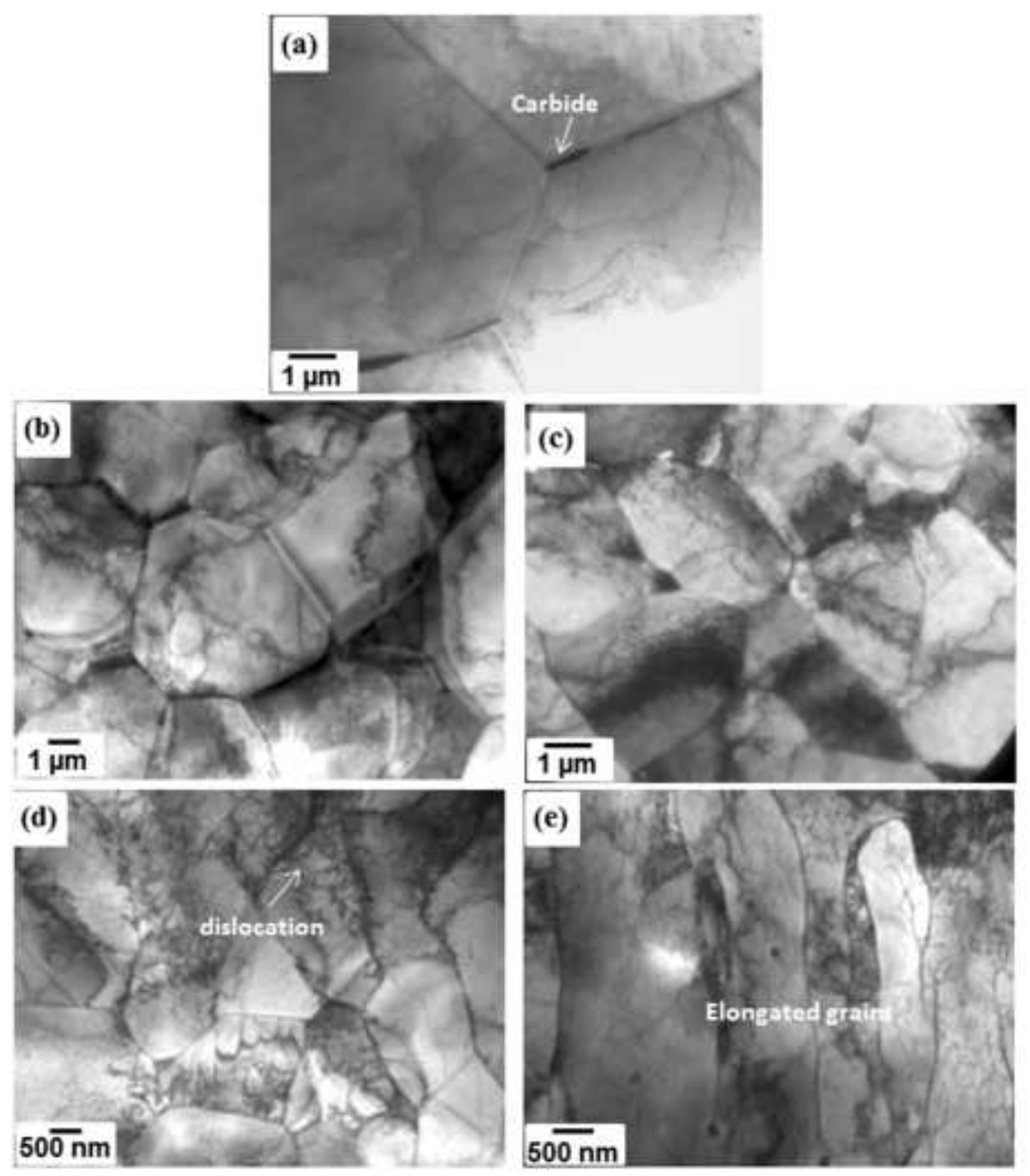

Fig. 9 


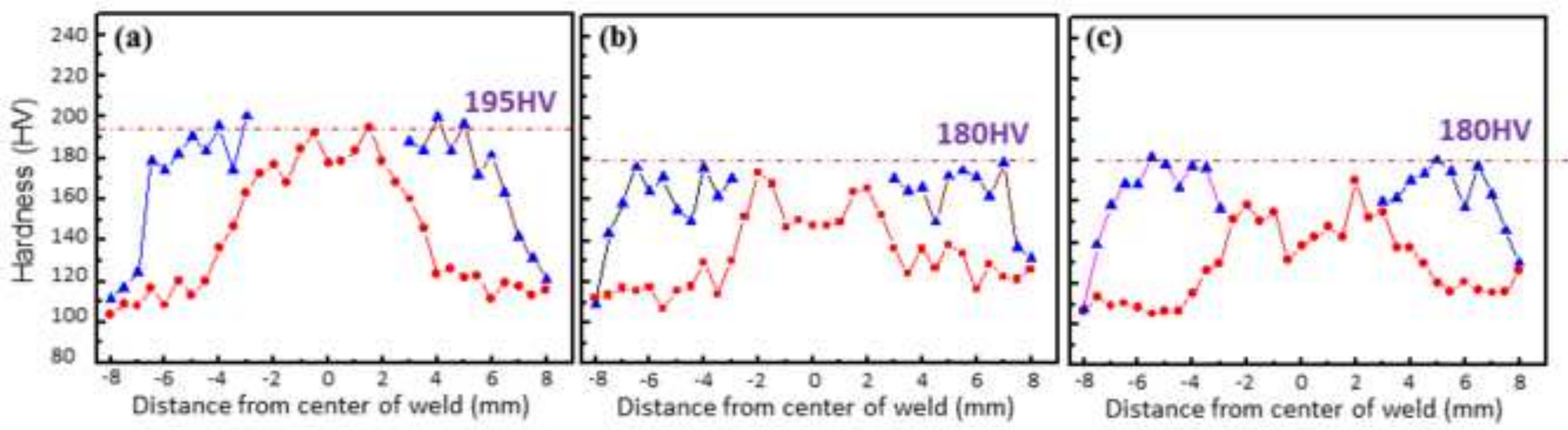

Fig. 10 


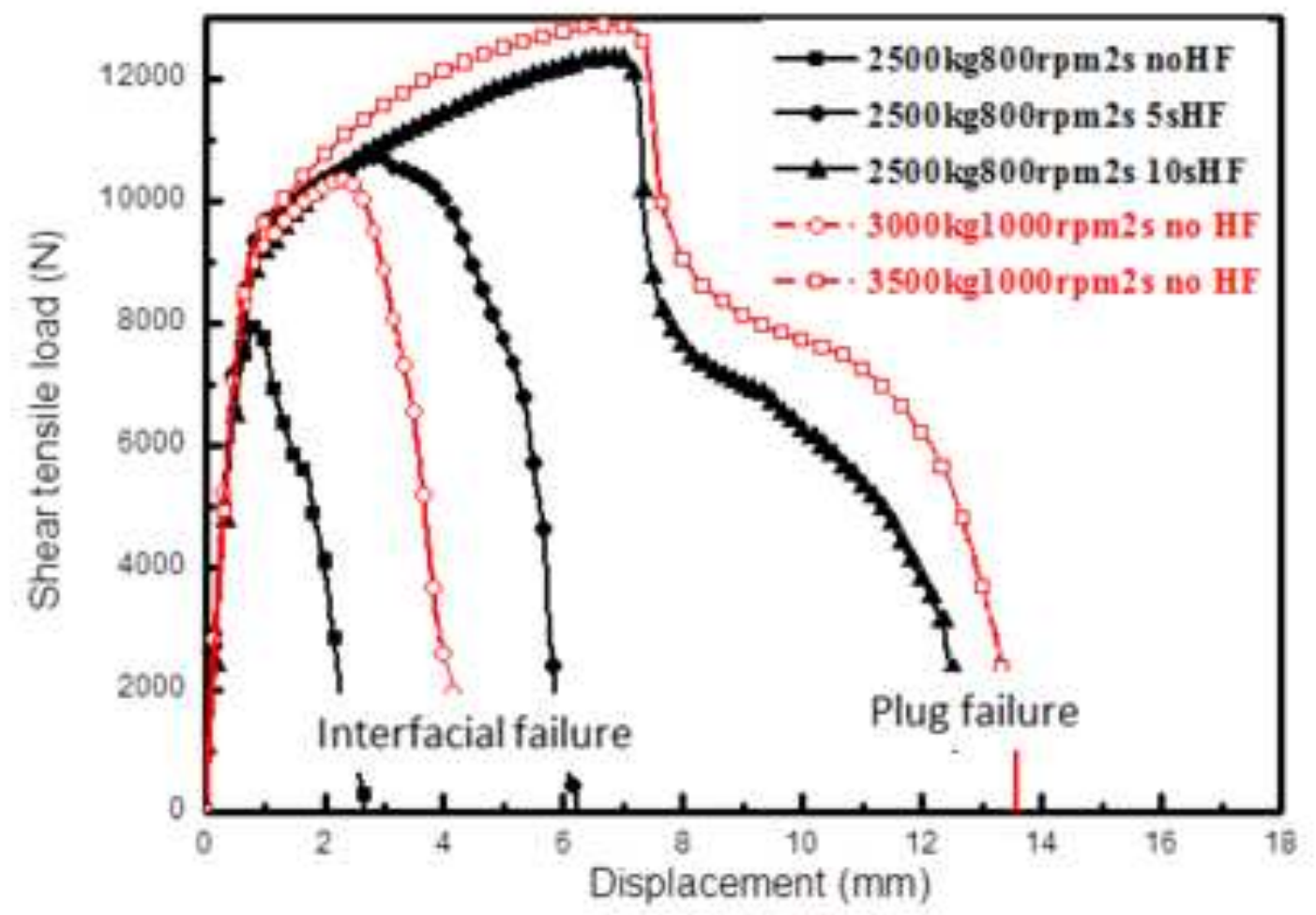

(a)

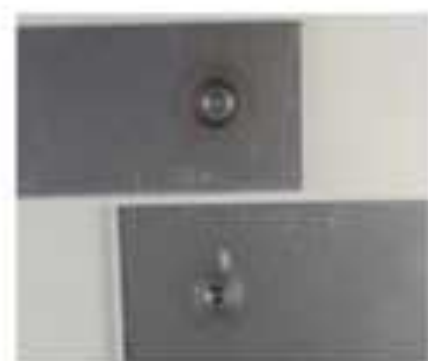

Interfacial failure

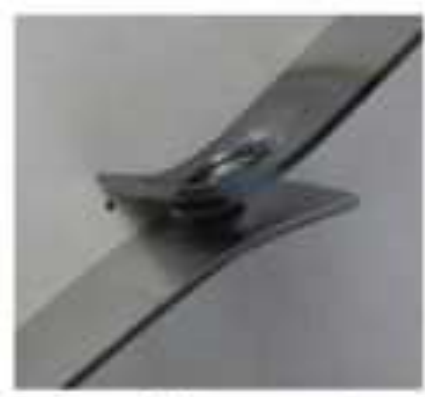

Plug failure mode

(b)

Fig. 11 